\title{
Validation of the
}

\section{cantharidin-induced skin}

\section{blister as an in vivo model of inflammation}

Correspondence

Dr Olivier Michel MD PhD, CHU

Brugmann/ULB - Université Libre de

Bruxelles, place Van Gehuchten, 4,

B -1020 Brussels, Belgium.

Tel.: +32 24772272

Fax: +32 24772276

E-mail:omichel@ulb.ac.be

Keywords

anti-TNF, blister, cantharidin,

inflammation, steroids

\section{Received}

22 November 2010

Accepted

13 May 2011

Accepted Article

19 May 2011

\section{WHAT IS ALREADY KNOWN ABOUT} THIS SUBJECT

- Techniques to create aseptic inflammatory reactions provide information regarding acute inflammatory pathways and may be used to assess the anti-inflammatory properties of novel drugs.

\section{WHAT THIS STUDY ADDS}

- In this study, we have shown that the cantharidin-induced blister is a local inflammatory reaction, safe and well tolerated, with a good intra-subject inter-day reproducibility. This induced blister is inhibited by specific (anti-tumour necrosis factor (TNF)) and non specific (corticosteroids) systemic anti-inflammatory agents. This model could be of interest to evaluate anti-inflammatory agents in their early phase development.

\section{AIM}

Pharmacological profiling techniques, such as the cantharidin-induced skin blister, may be used to assess the anti-inflammatory properties of novel drugs. However, no data are available on the reproducibility of this technique or on the blocking effect of anti-inflammatory drugs, such as anti-TNF and corticosteroids.

\section{METHODS}

A group of 30 healthy subjects were randomized into three parallel groups treated with placebo, oral methylprednisolone $20 \mathrm{mg} \mathrm{day}^{-1}$ for 7 days or anti-tumour necrosis factor (TNF) (adalimumab, Humira ${ }^{\circledR}$, Abbott) $40 \mathrm{mg}$ s.c. single dose. A first blister was induced at baseline and collected, immediately before the start of treatment and a second blister was obtained 7 days after the start of treatment. The total number of cells, the cell viability and the differential cell count were evaluated by two independent observers, who were blind to treatment. ANOVA was used to compare change from baseline among the three groups before pairwise comparisons.

\section{RESULTS}

Among the placebo group, there was no significant difference in the total cell count, neutrophils, eosinophils and monocytes between day 1 and day 7. Methylprednisolone inhibited the eosinophil influx in mean $\%(95 \% \mathrm{Cl})(-1.0(-1.7,-0.3) ; P<0.02)$ and absolute $(P<0.02)$ values, while anti-TNF inhibited the neutrophil influx in mean $\%(95 \% \mathrm{Cl})$ $(-19.3(-29.5,-9.1) ; P<0.01)$ and absolute $(P<0.05)$ values.

\section{CONCLUSIONS}

The cantharidin-induced skin blister is a safe, well tolerated and reproducible procedure. Pre-treatment with anti-TNF or methylprednisolone inhibited the neutrophilic or eosinophilic trafficking, respectively. It could be useful in profiling anti-inflammatory drugs regarding their effects on the cellular inflammatory response. 


\section{Introduction}

New drugs intended to treat inflammatory diseases are being developed to target the pathways of the inflammatory process. Controlled models of inflammation in humans are needed to screen for specific antiinflammatory effects of new agents [1]. Three models of innate inflammation are based on the exposure of humans to small amounts of bacterial components, the intravenous or inhaled endotoxin exposure and the cantharidininduced skin blister [2]. The skin blister model involves the topical application of the vesicant cantharidin to healthy skin, which causes in vivo leucocyte extravasation, cytokine release and clinical inflammation. Cantharidin is a defensive vesicant compound found within the haemolymph of blister beetles (Meloidae coleoptera). When applied to the skin it causes atraumatic acantholysis and blister formation. The technique has been standardized by Day et al. [3].

Techniques to create aseptic inflammatory reactions provide information regarding acute inflammatory pathways and may be used to assess the anti-inflammatory properties of novel drugs. For example, cantharidininduced inflammation has been used to characterize the anti-inflammatory properties of low dose of aspirin [4] or to elucidate some local endogenous anti-inflammatory mechanisms [5].

To validate the cantharidin-induced skin blister method, testing is necessary with model antiinflammatory agents. This was achieved by defining the inter- and intra-subject variability of the cantharidin- induced skin blister, and evaluating the blocking effects of the reference anti-inflammatory drugs, anti-tumour necrosis factor (TNF) and corticosteroids [6].

Therefore, the aim of the present study was to evaluate the inter- and intra-subject variability of the skin blister reaction and the protective effects of anti-TNF and oral corticosteroid, compared with placebo, in a group of healthy subjects.

\section{Methods}

\section{Subjects}

Thirty healthy, male and female, non-smoker volunteers were included after written informed consent was obtained from each subject (mean age 31.0 (28-34) years; F/M: 16/14). Subjects were excluded if they used drugs within 2 weeks or over the counter medication.

The challenge is essentially as described by Day et al. [3]. Briefly, a filter paper disc is placed on the volar forearm skin of the subject, and then impregnated with $25 \mu \mathrm{l}$ freshly prepared $0.1 \%(\mathrm{w} / \mathrm{v})$ cantharidin (Cantharone ${ }^{\circledR} \mathrm{R}$, Dormer Lab, Canada) in acetone (i.e. $25 \mathrm{mg}$ per blister) (Figure 1). This dose of cantharidin is approximately $15 \%$ of the dose used in over the counter preparations for verruca treatment. The disc is allowed to air dry while maintaining contact with the skin, and a blister dressing is applied. The blister fluid is harvested $24 \mathrm{~h}$ after cantharidin application. The side of the blister is pierced with a sterile needle and the liquid is collected using a Gilson pipette (after having
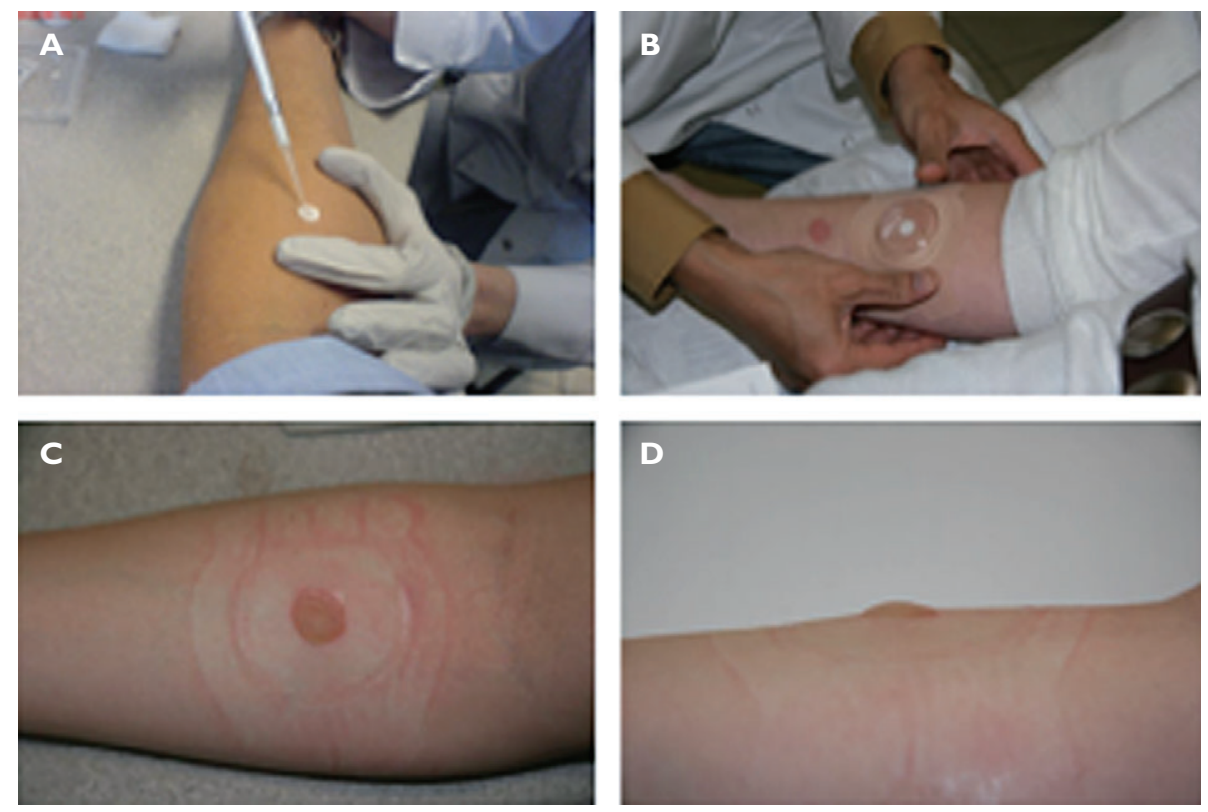

\section{Figure 1}

The procedure of the cantharidin-induced blister. (A) A filter paper disc is placed on the medium line of the forearm; $25 \mu \mathrm{l}$ of a $0.1 \%$ cantharidin solution in acetone is placed on to the filter paper disc; (B) Cover with an impermeable film and tape; then place a protective Pro-ophta eye dressing S cover; (C) By $24 \mathrm{~h}$ after induction there is a significant inflammation; (D) Blister shape 
applied a very light pressure on the surface of the blister with a pipette tip). The volume (evaluated by weighing) is generally between 100 and $800 \mu$ l. The liquid is kept on ice at all times.

After filtration and centrifugation $\left(400 \mathrm{~g}\right.$ at $4^{\circ} \mathrm{C}$ for $10 \mathrm{~min}$ ) the supernatant was frozen at $-80^{\circ} \mathrm{C}$ while the pelleted cells were resuspended in BSA/PBS. The total number of cells was measured with a Thoma haemocytometer. The cell viability was assessed by the blue trypan method. A slide was prepared by centrifugation (Cytospin, Shandon Inc, Pittsburgh, PA, USA) and stained with MayGrünwald-Giemsa. The differential cell count was based on 400 cells by two independent observers (the results had to differ by less than 10\%), who were blind to treatment.

\section{Study design}

The subjects were randomized into three open parallel groups treated with placebo, $20 \mathrm{mg}$ oral methylprednisolone (Medrol ${ }^{\circledR}$, Pfizer-Upjohn) once daily for 7 days or a single subcutaneous anti-TNF antibody, adalimumab (Humira ${ }^{\circledR}$, Abbott) on day 1.The first blister was induced on day 0 , around $08.00 \mathrm{~h}$, the liquid being collected the following day (day 1) at the same time of the day. This blister was defined as a control blister. The placebo and methylprednisolone treatments were given on days 1 (immediately after sampling of the control blister) to 7; the anti-TNF was injected on day 1. A second blister was induced on study day 6 on the forearm (at least $5 \mathrm{~cm}$ distance from the first blister) the liquid being sampled on day 7 after recording the maximal diameter. A clinical follow-up visit was performed after 5 weeks (on day 42).

\section{Good clinical practice}

This study was conducted in compliance with Good Clinical Practice Guidelines of the International Conference on Harmonization. The study (EudraCT: 2008-005526-37) was prior approved by the Ethics Committee of the Institution (decision number CE2008/49) and the competent authorities in Belgium. Written informed consent was obtained in each subject. The Clinical Research Unit of the Institution was responsible for study coordination.

\section{Statistics}

The results were expressed as mean or geometric mean \pm 95\% confidence interval $(\mathrm{Cl})$. The absolute values of the cells were log transformed to normalize their distribution. Repeatability was assessed by plotting the differences between repeated measurements against the mean of the repeated measures, and testing whether the mean differences were significantly different from 0 (method of Bland \& Altman) [7]. ANOVA was used to compare change from baseline among the three groups (placebo, methylprednisolone, anti-TNF). Pairwise comparisons between each active treatment and placebo, and between the two active treatments were performed. $P$ values smaller than 0.05 were considered statistically significant.

\section{Results}

All but one subject developed an evaluable blister reaction. The procedure was well tolerated; three subjects complained of a sensation of painless pulling of the skin during the procedure, which disappeared completely less than $24 \mathrm{~h}$ after blister collection. There were no systemic symptoms in any subject. A slight pigmentation was still observed at the follow-up visit (i.e. 35 days after the procedure) in two subjects.

The characteristics of each group are summarized in Tables 1 and 2. Before treatment, the blister size was 16.5 $(15.7,17.3) \mathrm{mm}$, and the volume of recovered liquid was $298(237,360) \mu \mathrm{l}$. The geometric mean of the total viable cells was $977(617,1549)$ cells $\mu l^{-1}$, with a viability of 97.7 $(95.6,99.8)$ and a differential of $74.2(68.4,80.1) \%$ polymorphonuclear neutrophils (PMN), $21.6(16.3,26.9) \%$ monocytes, 2.9 (1.9-3.8) \% lymphocytes and 1.1 (0.6-1.7) \% polymorphonuclear eosinophils (PME). There was no significant difference between males and females.

\section{Table 1}

Demography and blister characteristics before (controls) and after treatment (placebo, methylprednisolone (PDN), anti-TNF

\begin{tabular}{|c|c|c|c|c|}
\hline & Control & Placebo & PDN & anti-TNF \\
\hline Subjects & 30 & 10 & 10 & 10 \\
\hline Gender (F/M) & $16 / 14^{*}$ & $4 / 6$ & $5 / 5$ & $7 / 3$ \\
\hline Age (years, 95\% Cl) & $31(28,34)$ & $29(23,34)$ & $33(27,40)$ & $31(25,37)$ \\
\hline \multicolumn{5}{|c|}{ Blister size $(\mathrm{mm}, 95 \% \mathrm{Cl})$} \\
\hline Before & $16,5(15.7,17.3)$ & $17.3(15.7,18.8)$ & $16.1(14.5,17.7)$ & $16.1(14.4,17.7)$ \\
\hline After & $15.6(14.9,16.3)$ & $15.2(13.7,16.8) \dagger$ & $15.6(14.8,16.4)$ & $15.9(14.3,17.5)$ \\
\hline \multicolumn{5}{|c|}{ Blister volume $(\mu \mathrm{l}, 95 \% \mathrm{Cl})$} \\
\hline Before & $298(237,360)$ & $352(236,470)$ & $248(154,342)$ & $294(156,432)$ \\
\hline After & $211(176,245)$ & $227(152,302)$ & $202(154,250)$ & $203(127,279)$ \\
\hline
\end{tabular}

${ }^{*}$ Age, blister size and volume were not significantly different among females compared with males.

$+P<0.05$, paired $t$-test. 
Table 2

Blister cell counts before and after treatments

\begin{tabular}{|c|c|c|c|c|c|c|}
\hline Parametert & Total & Placebo (1) & PDN (2) & $P$ value $\ddagger(1)$ vs. (2) & anti-TNF (3) & $P$ value $\neq(1)$ vs. (3) \\
\hline \multicolumn{7}{|c|}{ Log viable cells (cells $\mu l^{-1}$ ) } \\
\hline Before & $2.99(2.79,3.19)$ & $2.96(2.45,3.47)$ & $3.11(2.82,3.40)$ & & $2.90(2.56,3.24)$ & \\
\hline After & $2.96(2.77,3.14)$ & $3.15(2.88,3.42)$ & $3.00(2.71,3.29)$ & & $2.72(2.27,3.17)$ & \\
\hline \multicolumn{7}{|c|}{ Log neutrophils (cells $\left.\mu\right|^{-1}$ ) } \\
\hline Before & $2.85(2.64,3.05)$ & $2.78(2.26,3.31)$ & $2.96(2.65,3.27)$ & & $2.79(2.45,3.14)$ & \\
\hline After & $2.76(2.56,2.97)$ & $2.96(2.67,3.25)$ & $2.85(2.49,3.21)$ & & $2.48(2.04,2.93)$ & \\
\hline Before & $0.71(0.44,0.98)$ & $0.28(-0.11,0.66)$ & $0.95(0.38,1.52)$ & & $0.90(0.45,1.36)$ & \\
\hline After & $0.37(0.11,0.63)$ & $0.43(-0.08,0.94)$ & $0.16(, 0.21,0.53)^{\star}$ & & $0.52(-0.08,1.13)$ & \\
\hline Change & $-0.34(-0.63,0.04)$ & $0.15(-0.23,0.53)$ & $-0.79(-1.28,0.29)$ & 0.004 & $-0.38(-1.0,0.24)$ & 0.12 \\
\hline \multicolumn{7}{|c|}{ Log monocytes (cells $\left.\mu\right|^{-1}$ ) } \\
\hline Before & $2.24(2.01,2.46)$ & $2.16(1.57,2.75)$ & $2.48(2.23,2.73)$ & & $2.07(1.69,2.45)$ & \\
\hline After & $2.36(2.18,2.54)$ & $2.53(2.25,2.82)$ & $2.29(2.09,2.49)$ & & $2.25(1.76,2.74)$ & \\
\hline Change & $0.12(-0.09,0.34)$ & $0.37(-0.06,0.80)$ & $-0.19(-0.49,0.11)$ & 0.03 & $0.18(-0.24,0.60)$ & 0.48 \\
\hline \multicolumn{7}{|c|}{ Neutrophils (\%) } \\
\hline Before & $74.2(68.4,80.1)$ & $72.7(55.9,89.4)$ & $71.3(65.4,77.1)$ & & $78.8(70.6,87.1)$ & \\
\hline After & $66.8(60.3,73.3)$ & $67.4(55.1,79.7)$ & $73.5(60.9,86.1)$ & & $59.6(48.0,71.1)^{* *}$ & \\
\hline Change & $-7.4(-14.3,0.54)$ & $-5.3(-17.2,6.7)$ & $2.3(-11.1,15.6)$ & 0.36 & $-19.3(-29.5,9.1)$ & 0.05 \\
\hline \multicolumn{7}{|c|}{ Eosinophils (\%) } \\
\hline Before & $1.1(0.6,1.7)$ & $0.5(0.0,1.0)$ & $1.5(0.0,3.0)$ & & $1.5(0.6,2.4)$ & \\
\hline After & $0.8(0.2,1.3)$ & $0.7(0.0,1.7)$ & $0.5(0.0,1.5)^{*}$ & & $1.2(0.0,2.3)$ & \\
\hline Change & $-0.4(-0.8,0)$ & $0.2(-0.3,0.7)$ & $-1.0(-1.7,0.3)$ & 0.004 & $-0.4(-1.1,0.3)$ & 0.15 \\
\hline \multicolumn{7}{|c|}{ Monocytes (\%) } \\
\hline Before & $21.6(16.3,26.9)$ & $23.0(7.8,38.2)$ & $24.5(19.0,30.0)$ & & $17.2(10.0,24.5)$ & \\
\hline After & $29.9(23.7,36.0)$ & $28.8(17.2,40.3)$ & $23.6(12.2,34.9)$ & & $37.3(25.7,48.8)^{* *}$ & \\
\hline Change & $8.3(1.8,14.7)$ & $5.8(-4.0,15.5)$ & $-1.0(-13.1,11.2)$ & 0.35 & $20.0(9.3,30.8)$ & 0.04 \\
\hline \multicolumn{7}{|c|}{ Lymphocytes (\%) } \\
\hline
\end{tabular}

${ }^{*} P<0.05 ; * * P<0.01$. Paired $t$-test to compare the blister cell counts before and after placebo, PDN and anti-TNF.

†Values are expressed as arithmetic mean (95\% confidence interval). PDN, methylprednisolone.

fUnpaired $t$-tests were used to compare the changes after placebo (1) with the changes after methylprednisolone (2) or anti-TNF (3).

The study population included 30 subjects who were randomized in a ratio 1:1:1 between three treatment groups: placebo, anti-TNF and oral corticosteroids. There was no significant difference between the groups regarding the size/volume or the cell counts of the control blisters before treatment. The intra-subject repeatability of the method was evaluated in the placebo group, by comparing the characteristics of the blisters on day 1 and day 7 (Figure 2). The Bland \& Altman analysis showed that the measurements of number of total cells, PMN, PME, monocytes, weight and size were not statistically different between day 1 and day 7 and the variability of measurement was not high thus suggesting good reliability of the method (Figure 2).

Drug effects were then evaluated for total cells, PMN, PME and monocytes. The oral corticosteroid treatment significantly inhibited the influx of eosinophils in the blister fluid and absolute values while it did not have any signifi- cant effect on total cells, monocytes or PMN (see Table 2 and Figure 3). The treatment with anti-TNF inhibited the influx of neutrophils in the blister fluid (both in \% and absolute value) and of monocytes (in \% but not in absolute value) while it did not have a significant effect on the total cells or on the absolute number of PME (see Table 2 and Figure 3). The diameter and/or volumes of the blisters were modified neither by oral corticosteroid, nor by anti-TNF (Table 1).

The changes of the cell counts after placebo were then compared (by repeated measures ANOVA) with the changes after treatment with corticosteroids or anti-TNF (Figure 4). The $F$-tests were significant for PMN \% $\left(F^{2}{ }_{27}=4.32, P=0.02\right)$, PME $\%\left(F^{2}{ }_{27}=4.63, P<0.02\right)$, mono $\%\left(F^{2}{ }_{27}=4.90, P=0.02\right)$, $\log$ PME $\left(F_{27}^{2}=4.87, P=0.02\right)$, and nearly significant for log PMN $\left(F_{27}^{2}=2.71, P=0.08\right)$ and log monocytes $\left(F_{27}^{2}=2.74, P\right.$ $=0.08$ ). The change of PMN count (both in absolute and \%) among the subjects treated with anti-TNF and the change 

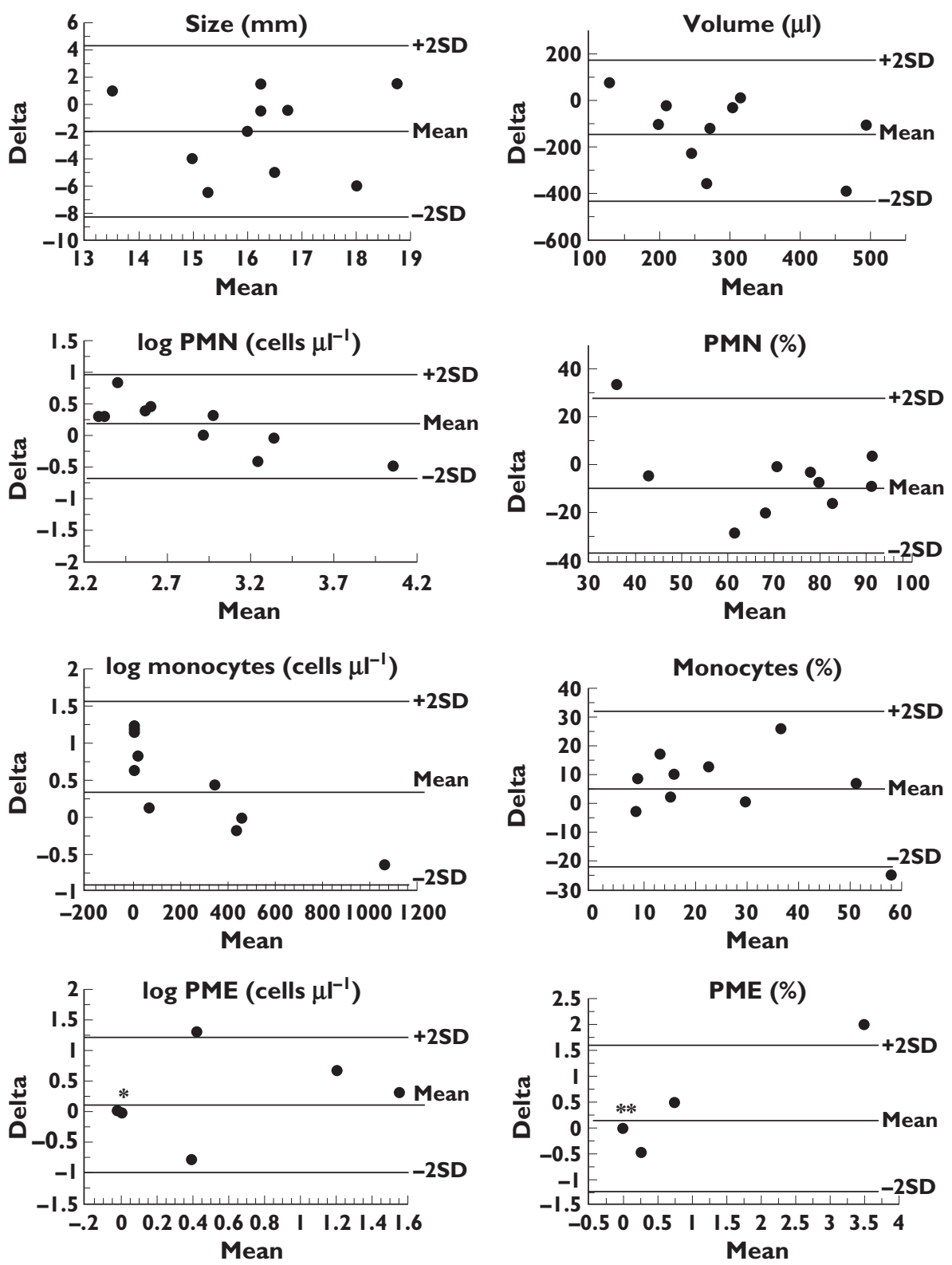

\section{Figure 2}

Assessment of repeatability of the cell counts of the blisters. The differences against the means, of the blister cells counts, between the day 1 and day 7 among the placebo group. Limits of agreement are the mean \pm 2 SD. ${ }^{*}$ and ${ }^{* *}$ includes five and seven subjects

of the PME count (both in absolute and \%) were statistically attenuated compared with placebo.

The individual values of the changes in PMN and PME after a treatment with oral corticosteroids or subcutaneous anti-TNF are shown in Figure 5.

\section{Discussion}

The results of the present study show that a) the cantharidin-induced skin blister is a safe and well tolerated procedure, b) the inter-subject variation of the amplitude of the clinical response is low, c) the intra-subject inter-day reproducibility of leucocyte accumulation in the blister fluid is significant, d) pre-treatment with methylprednisolone inhibits the eosinophilic inflammatory response and e) pre-teatment with the anti-TNF agent adalimumab inhibits neutrophil trafficking.

The skin-window chamber technique is based on a local injury to induce exudation and leucocyte migration. Originally, a physical trauma was applied either by abrasion [8], high-speed drill [9] or negative pressure [10]. In the 1960 s, a chemical method was published, based on the use of cantharidin causing acantholysis and blister formation 

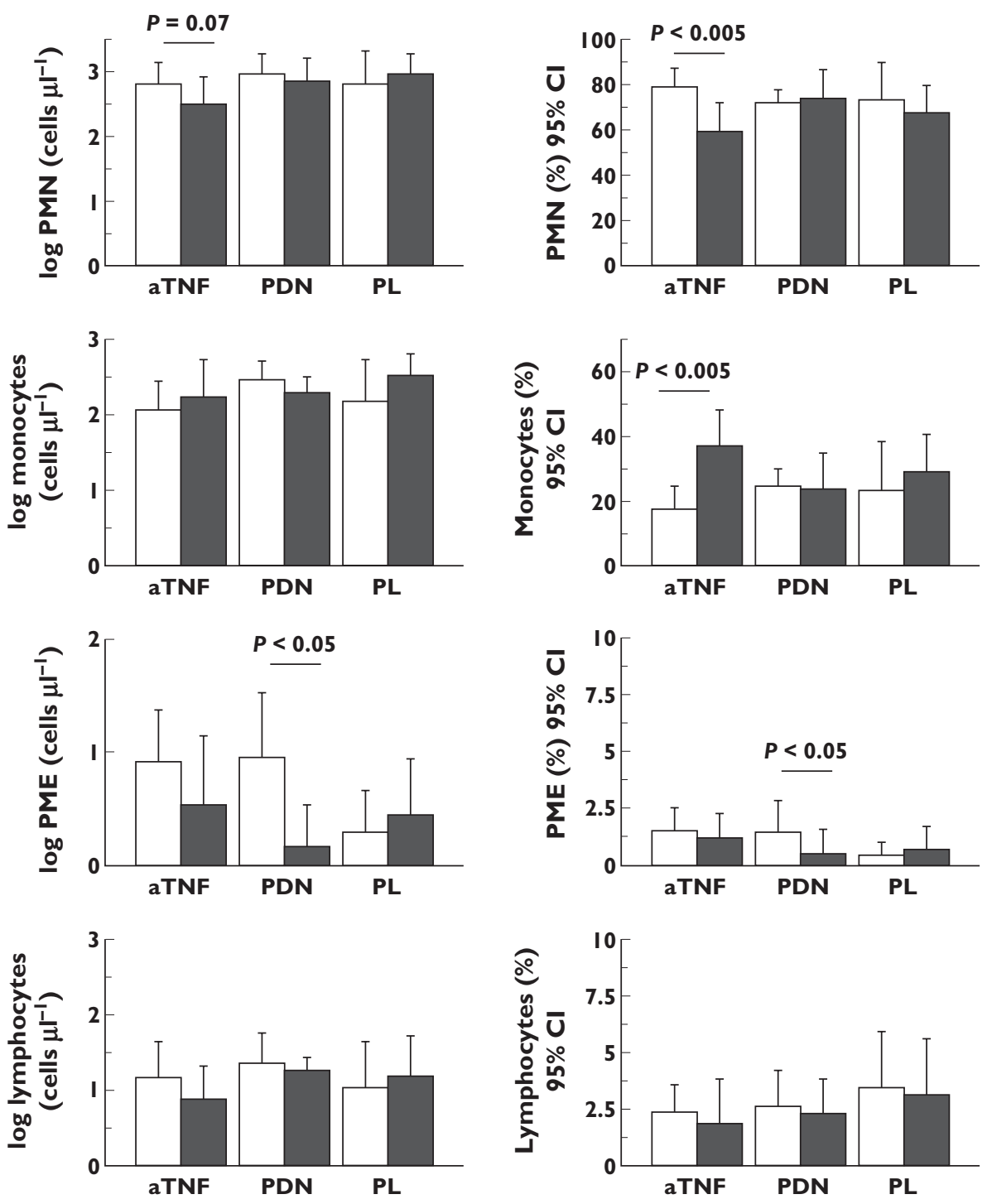

\section{Figure 3}

Cell counts before (white bar) and after treatment (black bar). Data are expressed as means $+95 \% \mathrm{Cl}$. Paired $t$-tests were used to assess whether mean changes from day 1 to day 7 were significantly different from zero by treatment. aTNF, anti-TNF; PDN, methylprednisolone; PL, placebo. PME, polymorphonuclear eosinophils; PMN, polymorphonuclear neutrophils

[11]. However, in the latter paper, the exudates were highly variable in the same subjects, probably because the method was not standardized, and the blisters were amplified by addition of bacterial antigens [11]. More recently, the cantharidin technique was revisited by Day et al. who reported a standardized procedure [3]. In a group of 12 healthy subjects they showed that the $24 \mathrm{~h}$ cantharidininduced blister was $1-2 \mathrm{~cm}$ diameter, $100-800 \mu$ l volume, about 2500 cells $\mu l^{-1}$ with a viability of $92-100 \%$ and a majority of PMN/PME (60-90\%), those characteristics being consistent with our results. The same study reported the presence of several inflammatory mediators in the blister fluid (mainly IL-8, ENA-78, GRO-a, C3a, TNF, II-12, II-1b [3].
The safety and tolerability of the cantharidin-induced blister challenge is very good. Discomfort, without pain, occurs for 2 days over the area of blistering. While the kinetics of leucocyte trafficking is subject-dependent [12], in our experience (see Table 1) the blister diameter and the weight of the liquid obtained at $24 \mathrm{~h}$ is very homogeneous between subjects. In our experience, the skin heals within 5 weeks. Hyper-pigmentation can occur, but persists no more than 6 months [3]. In fact, the concentration of cantharidin used in this study equates $25 \mathrm{mg}$ per blister, a seven-fold dilution of the pharmaceutical preparation used for plantar verrucae removal. There are very rare case reports of patients who developed acute cellulitis and/or lymphangitis soon after topical applica- 

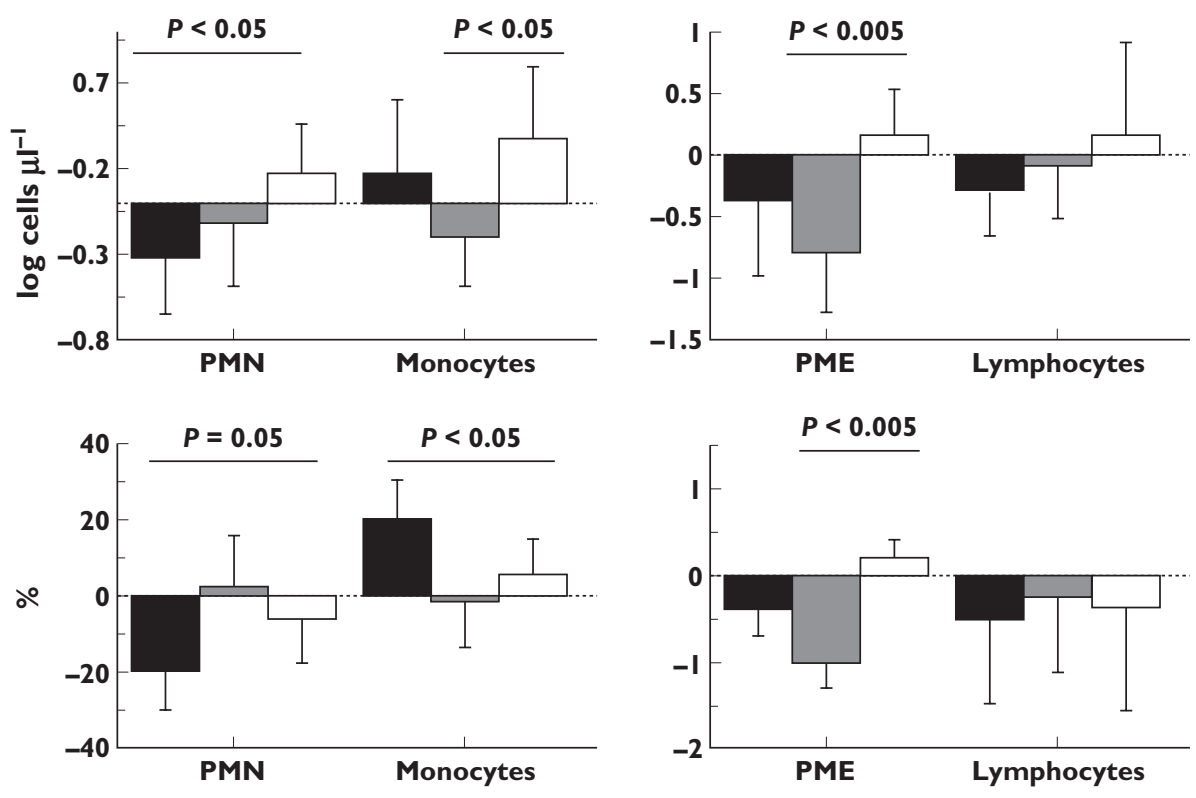

\section{Figure 4}

Comparison of the change of blister cell counts after each treatment. The black bar indicates the change after treating with anti-TNF, the grey bar is the change after methylprednisolone and the white bar is placebo. Data are expressed as means $+95 \% \mathrm{Cl}$. ANOVA among the three treatments was applied followed by comparisons among the treatments. PME, polymorphonuclear eosinophils; PMN, polymorphonuclear neutrophils
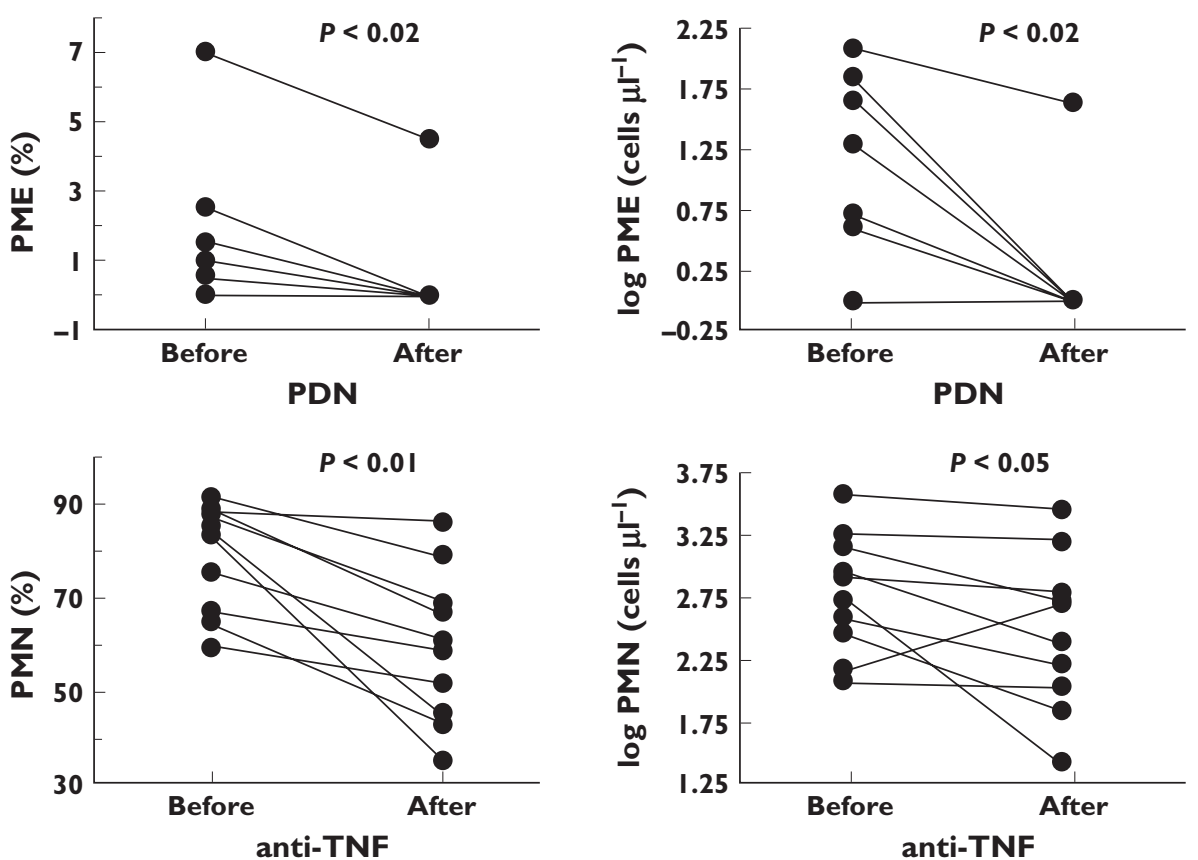

\section{Figure 5}

The drug effects in each subject. The absolute number (log transformed) and \% of neutrophils (PMN) and eosinophils (PME) measured in the cantharidininduced skin blister were compared by paired $t$-tests. PDN, methylprednisolone

tion of cantharidin for eradication of plantar verrucae [13]; therefore susceptible patients, in particular those with diabetes or peripheral arterial diseases, should not be studied.
Few data are available on the intra-subject reproducibility of the technique. Recently, Morris et al. have reported, in five subjects, that the total number of leucocytes is equivalent to two cantharidin-induced blisters at 1 
week's interval [12]. Our results show that the intra-subject reproducibility at a 7 days' interval is significant for the total leucocyte count and their differential and for the size of the blisters. This observation is important to validate this technique as a human non-invasive model of innate immunity [2] which could assess the anti-inflammatory properties of novel drugs. To assess the anti-inflammatory potential of novel compounds in healthy subjects given the selected immunological challenges, it is important to know the effect of proven reference therapies currently part of the standard of care for inflammatory diseases.

In the current study, the tested anti-inflammatory agents included methylprednisolone and an anti-TNF agent. Methylprednisolone is a synthetic corticosteroid with a large spectrum of anti-inflammatory properties, reducing tissue eosinophils in allergic responses by an apoptotic effect and an inhibitory effect on the medullar production [14]. In contrast to the effects on eosinophils, methylprednisolone increases the number of tissue neutrophils by increased survival [14]. Consistently, in clinical practice, methylprednisolone is efficaceous in eosinophilic inflammation, such as allergic asthma, whereas it fails to interfere with neutrophil-related inflammatory diseases such as chronic obstructive pulmonary disease. Therefore, the inhibiting effect of methylprednisolone at a daily dose of $20 \mathrm{mg}$ for 7 days (which is within the recommended dose range for severe asthma) on eosinophil number, accompanied with a rise of the percentage of neutrophils in the liquid of the cantharidin-induced blisters, is not a surprise. Other eosinophilic models are available, such as the allergen-induced nasal/bronchial inflammation. However the skin blister model is a tissue window on the inflammatory mechanisms, while the allergen induced response explores the inflammation outside of the tissue (at the extra-mucosal level).

Adalimumab is a complete human IgG1 anti-TNF $\alpha$ $\mathrm{mAb}$ which binds to the soluble and transmembrane forms of TNF $\alpha$ with high affinity, thereby preventing TNF $\alpha$ from binding to its receptors. In vitro studies have shown its effect on the induction of cell lysis and apoptosis. Exposure to adalimumab restores normal chemotactic neutrophil activity, decreases the influx of leucocytes to the inflamed joints, and reduces the activation marker CD69 on neutrophils in patients [15]. Consistently, in the present study, at a dose of $40 \mathrm{mg}$ (which is the recommended maintenance dose for severe rheumatoid arthritis, Crohn's disease and psoriasis), adalimumab attenuates the cantharidininduced blister neutrophilic inflammation.

Since we did not observe any effect which was common to the two test drugs in the cantharidin-induced blister challenge (in particular the monocytes), this method is not suitable as a general test of anti-inflammatory activity. However, for drugs that have been shown by other methods to possess anti-inflammatory activity, the cantharidin blister challenge can be used to characterize the cellular response.
Recently, the cantharidin-induced blister has been used as tissue injury model to demonstrate that aspirin, at low dose prevents leucocytes from accumulating by triggering epi-lipoxin [4] and that two phenotypes exist with regard to the kinetics of the inflammatory response to cantharidin which are associated with the blocking effect of aspirin [12]. Those observations also suggest that the cantharidininduced skin blister could be a promising model to evaluate anti-inflammatory agents in humans.

Another interesting feature of the skin blister is that it is a suitable technique for the assessment of peripheral compartment pharmacokinetics (PK), e.g. in saliva [16]. The PK profile of an antibiotic (meropenem) in blister fluid is also different compared with plasma. Therefore, the PK evaluated at the blister fluid level supports the dose in the management of skin and soft tissue infections [17].

The blister model could also contribute to understanding the mechanisms involved in some inflammatory diseases, such as Crohn's disease [18].

In conclusion, the cantharidin-induced blister is a safe and well tolerated, local inflammatory reaction, with a low inter-subject variability of the amplitude, a high intrasubject inter-day reproducibility and is inhibited by specific (anti-TNF) and non specific (corticosteroids) systemic anti-inflammatory agents. This model could be of interest to evaluate anti-inflammatory agents in their early phase development.

\section{Competing Interests}

There are no competing interests to declare.

Phong Huy Duc Dinh was supported by the CUD (Commission Universitaire au Développement). The study was supported by a grant from Funxional Therapeutics Ltd, Cambridge, United Kingdom. The statistical analysis has been reviewed by Ralitza Gueorguieva, Ph.D., Research Scientist in the Division of Biostatistics, Yale University School of Public Health.

\section{REFERENCES}

1 Groneberg DA, Chung KF. Models of chronic obstructive pulmonary disease. Respir Res 2004; 5: 18-34.

2 Fiuza C, Suffredini AF. Human models of innate immunity: local and systemic inflammatory responses. J Endotoxin Res 2001; 7: 385-8.

3 Day RM, Harbord M, Forbes A, Segal AW. Cantharidin blisters: a technique for investigating leukocyte trafficking and cytokine production at sites of inflammation in humans. J Immunol Methods 2001; 257: 213-20.

4 Morris T, Stables M, Hobbs A, de Souza P, Colville-Nash P, Warner T, Newson J, Bellingan G, Gilroy DW. Effects of 
low-dose aspirin on acute inflammatory responses in humans. J Immunol 2009; 183: 2089-96.

5 Philippidis P, Mason JC, Evans BJ, Nadra I, Taylor KM, Haskard DO, Landis RC. Hemoglobin scavenger receptor CD163 mediates interleukin-10 release and heme oxygenase-1 synthesis: antiinflammatory monocyte-macrophage responses in vitro, in resolving skin blisters in vivo, and after cardiopulmonary bypass surgery. Circ Res 2004; 94: 119-26.

6 Maglio D, Nightingale $\mathrm{CH}$, Nicolau DP. Production and resolution of cantharidin-induced inflammatory blisters. Int J Antimicrob Agents 2003; 22: 77-80.

7 Bland JM, Altman DG. Statistical methods for assessing agreement between two methods of clinical measurement. Lancet 1986; 1: 307-10.

8 Rebuck JW, Crowley JH. A method of studying leukocytic functions in vivo. Ann NY Acad Sci 1955; 59: 757-805.

9 Raeburn JA. A method for studying antibiotic concentrations in inflammatory exudate. J Clin Pathol 1971; 24:633-5.

10 Kiistala U, Mustakallio KK. In vivo separation of epidermis by production of suction blisters. Lancet 1964; 1: 1444-5.

11 Boggs DR, Athens JW, Haab OP, Raab SO, Cartwright GE, Wintrobe MM. Induced inflammatory exudates in normal man. A method designed to study the qualitative and quantitative cellular response to a pyogenic stimulus. Am J Pathol 1964; 44: 61-71.

12 Morris T, Stables M, Colville-Nash P, Newson J, Bellingan G, de Souza PM, Gilroy DW. Dichotomy in duration and severity of acute inflammatory responses in humans arising from differentially expressed proresolution pathways. Proc Natl Acad Sci USA 2010; 107: 8842-7.

13 Stazzone AM, Borgs $\mathrm{P}$, Witte $\mathrm{CL}$, Witte $\mathrm{MH}$. Lymphangitis and refractory lymphedema after treatment with topical cantharidin. Arch Dermatol 1998; 134: 104-6.

14 Schleimer RP, Spahn JD, Covar R, Szefler SJ. Glucocorticoids. In: Middleton's Allergy Principles and Practice, eds Adkinson NF, Yunginger JW, Busse WW et al. Philadelphia: Mosby, 2003; 870-913.

15 Wong M, Ziring D, Korin Y, Desai S, Kim S, Lin J, Gjertson D, Braun J, Reed E, Singh RR. TNF $\alpha$ blockade in human diseases: mechanisms and future directions. Clin Immunol 2008; 126 : 121-36.

16 Brunner M, Schmiedberger A, Schmid R, Jäger D, Piegler E, Eichler HG, Müller M. Direct assessment of peripheral pharmacokinetics in humans: comparison between cantharides blister fluid sampling, in vivo microdialysis and saliva sampling. Br J Clin Pharmacol 1998; 46: 425-31.

17 Maglio D, Teng R, Thyrum PT, Nightingale $\mathrm{CH}$, Nicolau DP. Pharmacokinetic profile of meropenem, administered at 500 milligrams every 8 hours, in plasma and cantharidin-induced skin blister fluid. Antimicrob Agents Chemother 2003; 47: 1771-3.

18 Harbord MW, Marks DJ, Forbes A, Bloom SL, Day RM, Segal AW. Impaired neutrophil chemotaxis in Crohn's disease relates to reduced production of chemokines and can be augmented by granulocyte-colony stimulating factor. Aliment Pharmacol Ther 2006; 24: 651-60. 